\title{
A Method of Microwave Soil Moisture Inversion without Dependence on the Field Measurement Data
}

\author{
HAN Lin ${ }^{1}$, CHEN Luwan ${ }^{1 *}$, ZHANG Yancheng ${ }^{1}$, QIN Xiaobao ${ }^{1}$ \\ ${ }^{1}$ College of Geology Engineering and Geomatics, Chang'an University, Shanxi Xi'an, 710064 China - chenluwan_online@163.com
}

\author{
Commission III, WG III/1
}

KEY WORDS: LUT, AIEM, Optimal effective roughness, Pixel scale, ASAR;

\begin{abstract}
:
In the process of retrieving soil moisture $\left(M_{v}\right)$ by active microwave, surface roughness is an important parameter affecting the accuracy of $m_{v}$ retrieval.Using effective roughness to replace the original measurement value of surface roughness can effectively avoid the error. In the existing methods of soil water inversion, the value of fixed mean square root height $(S)$ was used to retrieve the surface of different types and vegetation coverage, neglecting the difference of different ground surface. This paper proposed a LUT (look up table) soil moisture inversion method based on the pixel scale effective roughness. First, the effective roughness was obtained by using the measured soil moisture value of the sampling point based on the LUT method. And then the empirical function between the optimum roughness $(S$, Correlation length- $l$ ) and the backscattering coefficient of VV/HH polarization was obtained. The value of each pixel's S and L was obtained by using the empirical function. Finally, the soil moisture was retrieved by the LUT method. Using the measured data of the Linze sample area to verify, the results showed that the proposed method was superior to the LUT inversion method using the $S$ fixed value without dependence on the measured data of the roughness. It was also proved that the inversion method proposed in this paper is not only applicable to the bare soil area, but still maintained a high precision in the soil moisture inversion results in the area with large vegetation coverage.
\end{abstract}

\section{INTRODUCTION}

The spatial distribution of soil moisture is of great importance for drought detection, agricultural production, and field irrigation management, especially in the arid and semi-arid regions of northwest China. Active microwave remote sensing has the advantages of all-weather, multi-polarization, high resolution, penetration, and sensitive to moisture content. Therefore, active microwave remote sensing inversion of soil moisture is currently a research hotspot. In the field of active microwave remote sensing, Synthetic Aperture Radar (SAR) has become one of the most important frontier technologies in the field of Earth observation.

Surface roughness is an important parameter in soil moisture inversion. Prior studies (Li Zhen, 2011) showed that the effect of soil moisture on the backscatter coefficient is $5-7 \mathrm{~dB}$, but the effect of surface roughness on backscattering has reached $10 \mathrm{~dB}$ or more. The study of some researchers (Toan T L, 1999) shows that the error of soil moisture inversion mainly comes from the uncertainty of the measured roughness parameters. Verhoest and Lievens et al (Verhoest N E C, 2008; Lievens H, 2010a) also study on the effect of soil surface roughness measurement error on the inversion results of soil moisture, comprehensively described the method of characterization of surface roughness and related issues, and evaluated the effect of configuration parameters (single frequency, single polarization) with the SAR image on the inversion of soil moisture. Baghdadi et al conducted a sensitivity analysis of the radar frequency to soil parameters and found that the frequency has little effect on soil moisture and roughness parameters (Baghdadi N, 2002a). In order to achieve accurate inversion of soil moisture, it is necessary to accurately describe roughness and eliminate the influence of roughness.

In some studies, calibrated roughness parameters were used in place of the original soil roughness measurements. Baghdadi et al proposed scaling of roughness parameters, established the root mean square height $\mathrm{s}$ under multiple incident angle conditions, and optimized the correlation length Lopt (Baghdadi $\mathrm{N}, 2002 \mathrm{~b}, 2005,2011,2012$ ). The relationship maked the backscatter coefficient value simulated by the IEM model closer to the true value of the radar image, and the method for calculating the correlation length after the calibration by Baghdadi required the actually measured root mean square height to participate in the calculation. So the result of roughness parameter calibration would introduce measurement error; Lievens et al proposed an effective roughness method (Lievens H, 2010b). The C-band and L-band radar data were used to invert the soil moisture in the vegetation coverage area. This method could avoid the measurement error of the roughness. However, in calculating the effective correlation length, the root mean square height of the inversion region was fixed at a certain value, and then Effective correlation length was obtained by LUT method combined with measured soil moisture. Lievens considers that better accuracy of the inversion results could be obtained when $\mathrm{S}=1 \mathrm{~cm}$ for C-band, which neglected the difference of the different surface and would affect the accuracy of the inversion results.

To solve this problem, a LUT soil moisture inversion method based on pixel scale and effective roughness is proposed in this

\footnotetext{
* Corresponding author: CHEN Luwan, 1980.11, student pursuing a PhD degree of Chang'an University, Photogrammetry and remote sensing, The main research area is soil moisture retrieval by active microwave. Email:chenluwan_online@163.com
} 
paper. First, using a large number of field measured data and multiple SAR images, in view of the sampling points of different surface types and different vegetation coverage, the effective roughness is retrieved by LUT method and the measured soil moisture value at the sampling point in the range of $S \in(0.5 \mathrm{~cm}, 3.0 \mathrm{~cm})$ and $l \in(5 \mathrm{~cm}, 200 \mathrm{~cm})$. The optimal effective roughness of every sampling point is obtained according to the principle of the backscattering coefficient and the closest measurement of soil moisture in the LUT table. Then, it is found that there is a good empirical function among the optimal effective $S$ value, the optimal effective $l$ value and the VV/HH polarization backscattering coefficient of the bare soil and the vegetation cover. Through the empirical function, the optimal values of $S$ and $l$ of each pixel in the SAR image can be determined, and then the soil moisture is retrieved by LUT method. Using the measured data, the results show that the soil moisture inversion method based on the pixel scale effective roughness and the LUT proposed in this paper is suitable for the soil moisture inversion of the bare soil and the vegetation surface in arid and semi-arid areas. It can get high accuracy soil moisture retrieval results without relying on the measured data of surface roughness.

\section{STUDY AREA}

The study area in this paper is located in Gansu Province in northwestern China. The sample plots are located in the Linze plot in the middle reaches of the Heihe River, Arou Township, Ebao and Biandukou plots in the upper reaches of the Heihe River. The SAR image acquired by the ASAR sensor on the ESA's Envisat-1 satellite was selected as the data source for soil moisture inversion. The incident waveband of the ASAR image is $\mathrm{C}$-band ( $f=5.331 \mathrm{GHz})$, and there are 7 patterns of incident angles, covering the range of incident angles as $15^{\circ}-45^{\circ}$, and 5 operating modes (Image, Alternating Polarization, Wide Swath, Global Monitoring, and Wave). According to the radar angle of incidence, land cover type and month, seven scenes of ENVISAT ASAR images were selected. The images were acquired in October of 2007 and March, May, June and July of 2008. Table 1 shows the SAR data used in this study.

\begin{tabular}{|l|l|l|l|}
\hline ID & $\begin{array}{l}\text { Number } \\
\text { of } \\
\text { sampling } \\
\text { points }\end{array}$ & Date & $\begin{array}{l}\text { Radar } \\
\text { incidence } \\
\text { angle }\left(^{\circ}\right.\end{array}$ \\
\hline 1 & 50 & 2007.10 .17 & 23 \\
\hline 2 & 75 & 2007.10 .18 & 41 \\
\hline 3 & 41 & 2008.03 .12 & 23 \\
\hline 4 & 75 & 2008.06 .19 & 41 \\
\hline 5 & 25 & 2008.07 .05 & 44 \\
\hline 6 & 231 & 2008.07 .11 & 33.5 \\
\hline 7 & 132 & 2008.05 .24 & 19 \\
\hline \multicolumn{4}{|l}{} \\
\hline
\end{tabular}

The ground surface measurement data synchronized with the SAR satellite used in the experiment was derived from the "Watershed Allied Telemetry Experimental Research" (WATER) project. From the surface measured data provided by WATER project, the data of soil water content, root mean square height and correlation length observed synchronously with ASAR images were selected. A total of 18 samples and 629 sets of observations were selected for different areas, different months and different land cover types. There are many kinds of surface types in the sample area, including grassland, sparse vegetation, saline alkali land, alfalfa field, barley field, reed field, rape field, corn field and bare soil.

\section{STUDY ON THE OPTIMAL VALUE OF $S$ IN LUT METHOD}

At present, in the process of retrieving soil moisture by using LUT method, a fixed $S$ was used to establish LUT table for inversion. The surface difference was not taken into account. In fact, the results of soil moisture retrieval using different $S$ values in the same area were quite different. Figure 1 was the result of Soil Moisture Retrieval Based on the May 24, 2008 ASAR image and different $S$ values in Linze area.

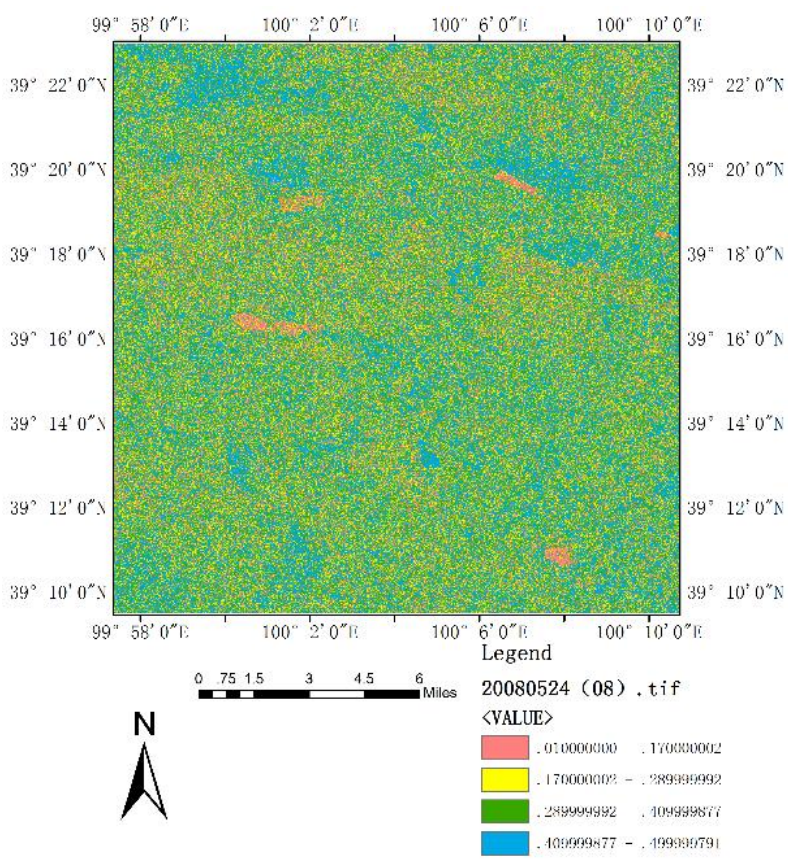

(a) $S=0.8 \mathrm{~cm}, R M S E=0.1422$

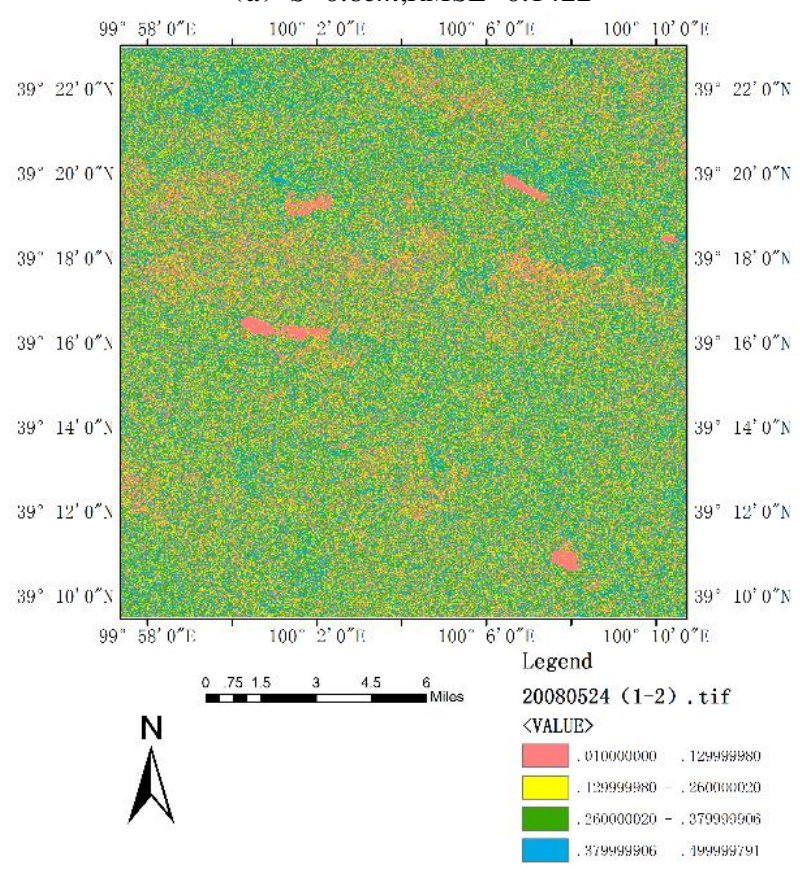




\section{(b) $S=1.2 \mathrm{~cm}, R M S E=0.1275$}

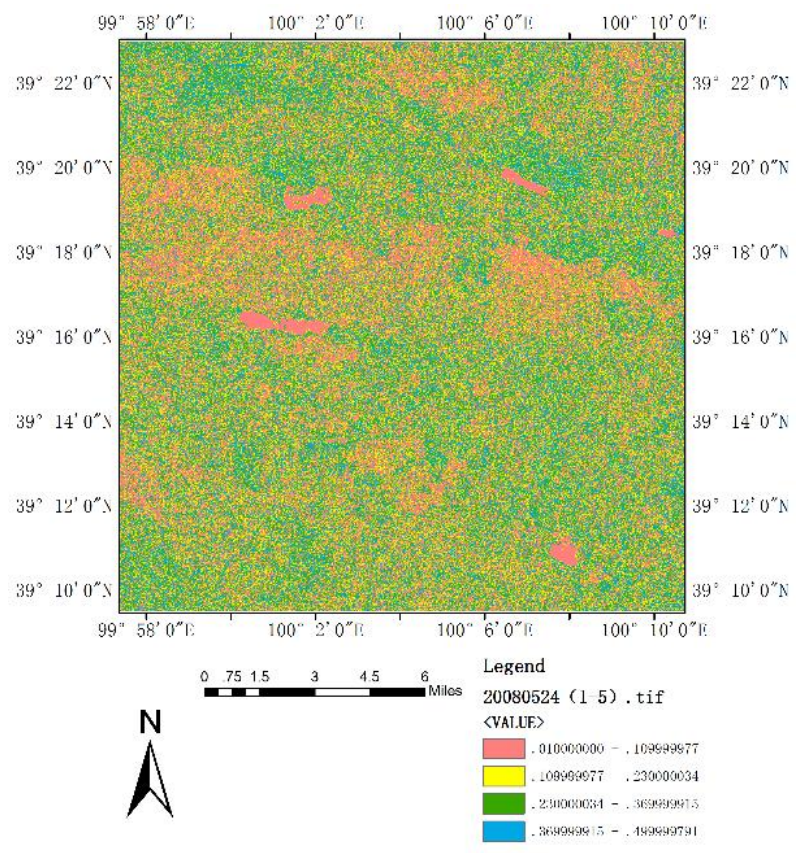

(c) $S=1.5 \mathrm{~cm}, R M S E=0.0786$

Figure 1.Results of soil moisture inversion in Linze area

As could be seen from Figure 1, the inversion results of LUT method based on fixed $S$ values showed that the soil moisture of the inversion decreased with the increase of $S$ value, and the accuracy of the inversion results was the best when $S=1.5 \mathrm{~cm}$. Therefore, it could be found that whether the $S$ value was suitable or not had great influence on the accuracy of LUT retrieving soil moisture.

\section{1 $S$ value experiment in LUT method based on different regions}

According to the different area of the land surface and vegetation coverage, the design experiment was carried out. Using the LUT method and measured data, the highest accuracy $S$ value of soil moisture retrieval results in different areas was obtained.

3.1.1 Setting the range of surface parameters in the experiment: According to the soil moisture and $S$ of the ground surface measured by 629 sampling points in 18 samples, $M_{v} \in(5 \%, 50 \%)$, the step length is $1 \% . S \in(0.1 \mathrm{~cm}, 3.5 \mathrm{~cm})$, the step length is $0.1 \mathrm{~cm}$, that is, the value of the root mean square height is 35 . According to the study results of Lievens ${ }^{[4]}, 5 \mathrm{~cm}$ $110 \mathrm{~cm}$ is suitable for the correlation length range, and the step length is $1 \mathrm{~cm}$. Table 2 is an introduction to the sample area data set selected for the experiment.

\begin{tabular}{|l|l|l|l|l|}
\hline No. & $\begin{array}{l}\text { Sampling } \\
\text { Area }\end{array}$ & $\begin{array}{l}\text { Sampling } \\
\text { Point }\end{array}$ & $\begin{array}{l}\text { Surface } \\
\text { Type }\end{array}$ & Month \\
\hline 1 & Ebo 1 & 25 & Meadow & 10 \\
\hline 2 & Biandukou 1 & 25 & Rape land & 10 \\
\hline 3 & Arou Pre- & 25 & Meadow & 10 \\
\hline
\end{tabular}

\begin{tabular}{|l|l|l|l|l|}
\hline & experiment 2 & & & Meadow \\
\hline 4 & $\begin{array}{l}\text { Arou Pre- } \\
\text { experiment 1 }\end{array}$ & 25 & 10 \\
\hline 5 & $\begin{array}{l}\text { Arou Pre- } \\
\text { experiment 2 }\end{array}$ & 25 & Meadow & 10 \\
\hline 6 & Arou 1 & 41 & $\begin{array}{l}\text { Snow- } \\
\text { covered } \\
\text { Meadow }\end{array}$ & 3 \\
\hline 7 & Arou 1 & 25 & Meadow & 6 \\
\hline 8 & Arou 2 & 25 & Meadow & 6 \\
\hline 9 & Arou 3 & 25 & Meadow & 6 \\
\hline 10 & $\begin{array}{l}\text { Arou Pre- } \\
\text { experiment 1 }\end{array}$ & 25 & Meadow & 7 \\
\hline 11 & Linze A & 44 & Reed & 7 \\
\hline 12 & Linze B & 41 & Meadow & 7 \\
\hline 13 & Linze C & 48 & $\begin{array}{l}\text { Saline } \\
\text { Land }\end{array}$ & 7 \\
\hline 14 & Linze D & 49 & $\begin{array}{l}\text { Alfalfa } \\
\text { Land }\end{array}$ & 7 \\
\hline 15 & Linze E & 49 & $\begin{array}{l}\text { Barley } \\
\text { Land }\end{array}$ & 7 \\
\hline 16 & Linze B & 48 & $\begin{array}{l}\text { Saline } \\
\text { Land }\end{array}$ & 5 \\
\hline 17 & Linze D & 49 & $\begin{array}{l}\text { Alfalfa } \\
\text { Land }\end{array}$ & 5 \\
\hline 18 & Linze E & 35 & $\begin{array}{l}\text { Barley } \\
\text { Land }\end{array}$ & 5 \\
\hline
\end{tabular}

Table 2. Introduction of Sampling areas

3.1.2 Soil moisture inversion based on LUT method: The AIEM model is used to simulate the back scattering coefficient of VV polarization, and the LUT table of the VV polarization backscattering coefficient is set up by $35 \mathrm{~S}$ values respectively. In the LUT table, the cost function is used to retrieve the soil moisture in the 18 sampling areas.

The cost function is as follows:

$$
\sigma_{\min }^{0}=\min \left(\sqrt{\left(\sigma_{V V, M}^{0}-\sigma_{V V, A I E M}^{0}\right)^{2}}\right)
$$

Where $\quad \sigma_{V V, M}^{0}=$ the same polarization backscatter coefficient obtained from SAR images

$$
\sigma_{V V, A I E M}^{0}=\text { the same polarization backscatter }
$$

coefficient simulated by AIEM model

$\sigma_{\min }^{0}=$ the minimum cost back scattering

coefficient

According to the RMSE between the soil moisture retrieval result obtained from different $S$ values and the measured value, The $S$ value with the highest inversion accuracy is selected. Table 3 is the optimal $S$ value for the different areas. 
The International Archives of the Photogrammetry, Remote Sensing and Spatial Information Sciences, Volume XLII-3, 2018 ISPRS TC III Mid-term Symposium “Developments, Technologies and Applications in Remote Sensing”, 7-10 May, Beijing, China

\begin{tabular}{|l|l|l|l|l|l|}
\hline No. & Month & Sampling Area & Surface Type & $\begin{array}{l}\text { Angle of } \\
\text { incidence }^{\circ} \text { ) }\end{array}$ & $\begin{array}{l}\text { Optimal } S \\
\text { value(cm) }\end{array}$ \\
\hline 1 & 10 & Ebo 1 & Meadow & 41 & 0.1 \\
\hline 2 & 10 & Biandukou 1 & Rape land & 23 & 2.1 \\
\hline 3 & 10 & $\begin{array}{l}\text { Arou Pre- } \\
\text { experiment 2 }\end{array}$ & Meadow & 23 & 0.1 \\
\hline 4 & 10 & $\begin{array}{l}\text { Arou Pre- } \\
\text { experiment 1 }\end{array}$ & Meadow & 41 & 0.1 \\
\hline 5 & 10 & $\begin{array}{l}\text { Arou Pre- } \\
\text { experiment 2 }\end{array}$ & Meadow & 41 & 0.1 \\
\hline 6 & 3 & Arou 1 & $\begin{array}{l}\text { Snow-covered } \\
\text { Meadow }\end{array}$ & 23 & 0.3 \\
\hline 7 & 6 & Arou 1 & Meadow & 41 & 2.1 \\
\hline 8 & 6 & Arou 2 & Meadow & 41 & 2.7 \\
\hline 9 & 6 & Arou 3 & Meadow & 41 & 1 \\
\hline 10 & 7 & $\begin{array}{l}\text { Arou } \\
\text { experiment 1 }\end{array}$ & Meadow & 44 & 0.7 \\
\hline 11 & 7 & Linze A & Reed & 33.5 & 0.2 \\
\hline 12 & 7 & Linze B & Meadow & 33.5 & 0.8 \\
\hline 13 & 7 & Linze C & Saline Land & 33.5 & 0.5 \\
\hline 14 & 7 & Linze D & Alfalfa Land & 33.5 & 0.3 \\
\hline 15 & 7 & Linze E & Barley Land & 33.5 & 2.9 \\
\hline 16 & 5 & Linze B & Saline Land & 19 & 0.8 \\
\hline 17 & 5 & Linze D & Alfalfa Land & 19 & 0.4 \\
\hline 18 & 5 & Linze E & Barley Land & 19 & 1.2 \\
\hline
\end{tabular}

Table.3 The optimal $S$ value table for different areas

Table 3 shows that the optimal $S$ value is different for different land types and vegetation coverage areas. The same surface types, such as 3, 4, 5 areas in Table 3, are all grassland types. The optimal $S$ value is $0.1 \mathrm{~cm}$. But the 7,8 and 9 areas in Table 3 are all grassland types, the optimal $S$ values are different. Similarly, the optimal $S$ value of 15 and 18 areas of barley land is also different. Therefore, it is not appropriate to take the same $S$ value in the same surface type area, and it is necessary to study the optimal $S$ value based on pixel scale.

\section{2 $S$ value experiment in LUT method based on different sampling points}

The experiment was designed for different sampling points. Using the LUT method and measured data, the highest accuracy
$S$ value of soil moisture retrieval of each sampling point was obtained.

3.2.1 Setting the range of surface parameters in the experiment: According to the measured soil moisture and the root height of the earth's surface, the range of soil moisture and $S$ values were determined according to the measured soil moisture and $S$ values of the 629 sets of sampling points in the different areas. The step length of $S$ is $1 \mathrm{~cm}$, the step length of $M_{v}$ is $1 \%$. The range of correlation length is $5-110 \mathrm{~cm}$ and the step length is $1 \mathrm{~cm}$. Table 4 is the range of surface parameters for different areas.

\begin{tabular}{|l|l|l|l|}
\hline No. & Sampling Area & $\begin{array}{l}\text { Range of } S \\
\text { value(cm) }\end{array}$ & $\begin{array}{l}\text { Range of } \\
M_{v} \\
\text { value(\%) }\end{array}$ \\
\hline 1 & Ebo 1 & $0.3-2.5$ & $30-45$ \\
\hline 2 & Biandukou 1 & $0.5-2.8$ & $15-35$ \\
\hline 3 & $\begin{array}{l}\text { Arou Pre- } \\
\text { experiment 2 }\end{array}$ & $0.3-2.5$ & $30-50$ \\
\hline 4 & $\begin{array}{l}\text { Arou Pre- } \\
\text { experiment 1 Pre- }\end{array}$ & $0.3-3.0$ & $35-55$ \\
\hline 5 & $\begin{array}{l}\text { Arou } \\
\text { experiment 2 }\end{array}$ & $0.3-2.5$ & $30-55$ \\
\hline 6 & Arou 1 & $0.3-3.0$ & $10-40$ \\
\hline 7 & Arou 1 & $0.3-2.0$ & $5-30$ \\
\hline 8 & Arou 2 & $0.5-2.5$ & $10-30$ \\
\hline 9 & Arou 3 &
\end{tabular}




\begin{tabular}{|l|l|l|l|}
\hline 10 & $\begin{array}{l}\text { Arou Pre- } \\
\text { experiment 1 }\end{array}$ & $0.3-3.0$ & $20-40$ \\
\hline 11 & Linze A & $0.3-3.0$ & $20-65$ \\
\hline 12 & Linze B & $0.5-3.0$ & $20-50$ \\
\hline 13 & Linze C & $0.5-3.0$ & $30-50$ \\
\hline 14 & Linze D & $0.5-3.0$ & $30-60$ \\
\hline 15 & Linze E & $0.5-3.0$ & $10-60$ \\
\hline 16 & Linze B & $0.5-3.0$ & $10-55$ \\
\hline 17 & Linze D & $0.5-3.0$ & $10-55$ \\
\hline 18 & Linze E & $0.5-3.0$ & $10-55$ \\
\hline
\end{tabular}

Table.4 The range of surface parameters for different areas

According to the measured soil moisture and root mean square height of the 629 sampling points, the soil moisture range is $5 \%-50 \%$ and the step length is $1 \%$. The height of the square root is $0.1-3.5 \mathrm{~cm}$ and the step length is $0.1 \mathrm{~cm}$, that is, the number of root mean square heights is 35.According to Lievens's experiment results ${ }^{[198]}$, it is appropriate to use a range of 5 to $10 \mathrm{~cm}$ for the relevant length, with a step length of $1 \mathrm{~cm}$. Major headings are to be centered, in bold capitals without underlining, after two blank lines and followed by a one blank line.

\subsubsection{Optimal roughness inversion based on LUT method:} The AIEM model was used to simulate the VV/HH polarization backscattering coefficient, and the LUT table of the VV/HH polarization direction scattering coefficient was established by the value of each square root height in the different region respectively. In the LUT table, when the value of different $S$ was taken, the cost function was first used to select the record which was closest to the true backscatter coefficient of the backscatter coefficient and the sampling point in the LUT table.Then the simulated soil moisture was compared with the measured soil moisture in these records. The values of $S$ and $l$ in these records closest to the measured soil moisture were selected, which was the optimal value of $S$ and $l$.

The cost function is as follows:

$$
\sigma_{\min }^{0}=\min \left(\sqrt{\left(\sigma_{V V, M}^{0}-\sigma_{V V, A I E M}^{0}\right)^{2}+\left(\sigma_{H H, M}^{0}-\sigma_{H H, A I E M}^{0}\right)^{2}}\right)
$$

where $\quad \sigma_{V V, M}^{0}=$ the $\mathrm{VV}$ polarization backscatter coefficient obtained from SAR images $\sigma_{V V, A I E M}^{0}=$ the $\mathrm{VV}$ polarization backscatter coefficient simulated by AIEM model $\sigma_{H H, M}^{0}=$ the $\mathrm{HH}$ polarization backscatter coefficient obtained from SAR images $\sigma_{H H, A I E M}^{0}=$ the $\mathrm{HH}$ polarization backscatter coefficient simulated by AIEM model $\sigma_{\min }^{0}=$ the minimum cost back scattering coefficient

Table 5 is the optimal roughness values for partial sampling points.

\begin{tabular}{|l|l|l|l|}
\hline $\begin{array}{l}\text { Sampling } \\
\text { Area }\end{array}$ & $\begin{array}{l}\text { Sampling } \\
\text { Point ID }\end{array}$ & $\begin{array}{l}\text { the optimal } \\
\text { effective } S\end{array}$ & $\begin{array}{l}\text { the } \\
\text { optimal } \\
\text { effective } l\end{array}$ \\
\hline Linze & 1 & 0.4 & 18 \\
\cline { 2 - 4 } A(11) & 2 & 1 & 32 \\
\hline
\end{tabular}

\begin{tabular}{|l|l|l|l|}
\hline \multirow{4}{*}{} & 3 & 1.1 & 46 \\
\cline { 2 - 4 } & 4 & 0.2 & 5 \\
\cline { 2 - 4 } & 5 & 1.8 & 57 \\
\cline { 2 - 4 } & 6 & 0.5 & 9 \\
\cline { 2 - 4 } & 7 & 0.4 & 5 \\
\cline { 2 - 4 } & 8 & 0.5 & 10 \\
\cline { 2 - 4 } & 9 & 1.1 & 29 \\
\cline { 2 - 4 } & 10 & 1 & 16 \\
\hline \multirow{5}{*}{ Binze } & 1 & 1.80 & 5.00 \\
\cline { 2 - 4 } & 2 & 1.00 & 24.00 \\
\cline { 2 - 4 } & 3 & 0.70 & 14.00 \\
\cline { 2 - 4 } & 4 & 1.90 & 67.00 \\
\cline { 2 - 4 } & 5 & 0.70 & 5.00 \\
\cline { 2 - 4 } & 6 & 1.20 & 34.00 \\
\cline { 2 - 4 } & 7 & 2.50 & 27.00 \\
\cline { 2 - 4 } & 8 & 1.30 & 16.00 \\
\cline { 2 - 4 } & 9 & 0.50 & 5.00 \\
\cline { 2 - 4 } & 10 & 1.70 & 17.00 \\
\hline
\end{tabular}

Table.5 The optimal roughness values for partial sampling points

3.2.3 Construction of the best roughness inversion experience function: The relationship among the optimal $S$ value, the optimal $l$ value, the backscatter coefficient $\sigma_{v v}^{0}$ and $\sigma_{h h}^{0}$ in various areas was studied. Through multiple regression statistics, it was found that there was the following relationship among $S, l, \sigma_{v v}^{0}$ and $\sigma_{h h}^{0}$ :

$$
\begin{gathered}
\sigma_{v v}^{0}=A S+B l+C \\
\sigma_{h h}^{0}=D S+E l+F
\end{gathered}
$$

where $\quad \sigma_{v v}^{0}=$ the backscattering coefficient of $\mathrm{VV}$ polarization modes

$$
\sigma_{h h}^{0}=\text { the backscattering coefficient of } \mathrm{HH}
$$

polarization modes

$$
A, B, C, D, E, F=\text { the empirical }
$$

coefficients

By using the optimal $S$ and $l$ values obtained by inversion and backscatter coefficients, we can get the empirical coefficients $A, B, C, D, E, F$ in the formula(3) and (4) 
by multiple linear regression analysis.Formula (3) and (4) join together could get the optimal $S$ and $l$ values of each pixel.

\subsection{Soil moisture inversion based on LUT method}

In the inversion region of the measured data without roughness, the optimal $S$ and $l$ values of each pixel in the image are obtained by the back scattering coefficient and the formula (3) and (4). The parameters in the AIEM model are soil moisture, $S$, $l$ and backscatter coefficient. The coefficient of backscattering coefficient can be obtained by processing radar images, and $S$ and $l$ have been obtained. At this time, the unknown parameter is soil moisture, and LUT method is used to solve the soil moisture.

\section{RESULTS AND ANALYSIS}

\subsection{Verification result}

The A, B and C of Linze sample area in July 11, 2008 were selected for verification. The surface area of $A$ was reed and the range of NDVI value was 0.3-0.9. The surface type of B is grassland, and the range of NDVI value is $0.1-0.35$. The $\mathrm{C}$ in the sample area is saline alkali soil, and the range of NDVI value is $0.1-0.3$. Using the LUT method based on fixed $S$ value, the soil moisture is retrieved from the selected three sample regions, and the fixed $S$ values can be obtained according to table 3. The $S$ values of the three samples of A, B and C are $0.2 \mathrm{~cm}, 0.8 \mathrm{~cm}$ and $0.5 \mathrm{~cm}$ respectively. Then, soil moisture retrieval in three sampling areas is carried out by using the method proposed in this paper.

Figure 2 is the result of soil moisture inversion of the two methods. (a) is the inversion result of the LUT method when the $S$ value is fixed based on area A. (b) is the inversion result using the new method of this paper based on area A. (c) is the inversion result of the LUT method when the $S$ value is fixed based on area B. (d) is the inversion result using the new method of this paper based on area B. (e) is the inversion result of the LUT method when the $S$ value is fixed based on area C. (f) is the inversion result using the new method of this paper based on area $\mathrm{C}$.
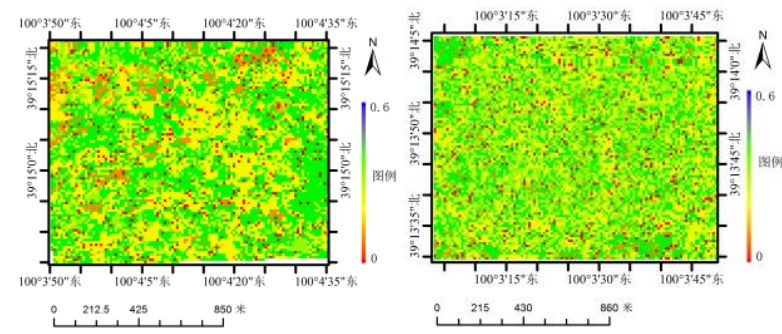

(a) $\mathrm{S}=0.2 \mathrm{~cm}(\mathrm{~A})$

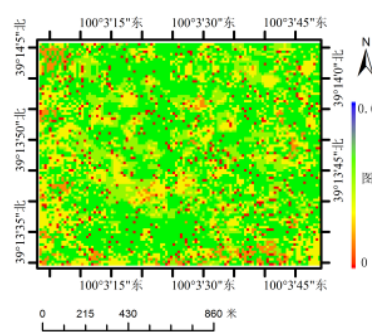

(b) new $\operatorname{method}(\mathrm{A})$

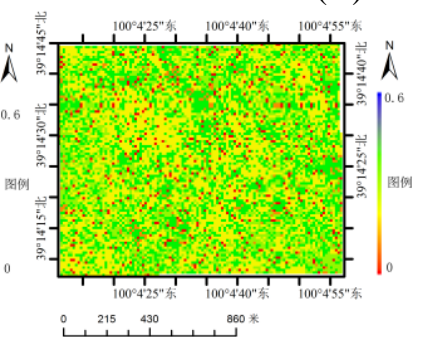

(c) $\mathrm{S}=0.8 \mathrm{~cm} \quad(\mathrm{~B})$

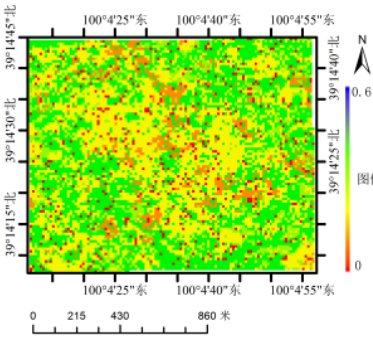

(e) $\mathrm{S}=0.5 \mathrm{~cm}(\mathrm{C})$ (d) new method(B)

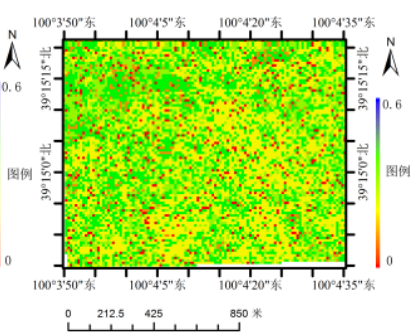

(f) new method (C)
Figure 2.Result of soil moisture inversion of the two methods in Linze area

\subsection{Analysis}

The accuracy is verified by the verification points in the sample area. In Table 6 , the correlation coefficient $R^{2}$ and RMSE between the soil moisture inversion and the measured values are given. The test results show that the inversion results obtained by the proposed method are consistent with the measured values, and the inversion accuracy is higher.

\begin{tabular}{|l|l|l|l|l|}
\hline $\begin{array}{l}\text { Sampling } \\
\text { Area }\end{array}$ & $\begin{array}{l}\text { Fixed } S \\
\text { value }\left(R^{2}\right)\end{array}$ & $\begin{array}{l}\text { Fixed } \\
\text { value } \\
(\text { RMSE })\end{array}$ & $\begin{array}{l}\text { New } \\
\text { method } \\
\left(R^{2}\right)\end{array}$ & $\begin{array}{l}\text { New } \\
\text { method } \\
(\text { RMSE) }\end{array}$ \\
\hline Linze A & 0.5922 & 0.1081 & 0.7101 & 0.0712 \\
\hline Linze B & 0.6623 & 0.1183 & 0.7891 & 0.0681 \\
\hline Linze C & 0.6912 & 0.1005 & 0.8440 & 0.0525 \\
\hline \multicolumn{5}{|c|}{ Table.6 Comparison of inversion accuracy }
\end{tabular}

Table 6 shows that the inversion method based on the pixel scale effective roughness and LUT based on the pixel scale proposed in this paper has high inversion accuracy. It is not only applicable to the inversion of soil moisture on the bare soil surface in arid and semi-arid areas, but also suitable for the areas with higher vegetation coverage, and the results of high precision soil moisture inversion can be obtained.

\section{CONCLUSION}

In view of the problem of neglecting different surface differences in the existing effective roughness inversion method, this paper selects several kinds of surface types common in arid and semi-arid areas to carry out a large number of experiments, obtain the optimum roughness values of different types of areas, and then construct the empirical function between $S, l$ and backscatter coefficients. Soil moisture inversion was carried out by LUT method. After verification, the inversion accuracy of this method is high, and it can be applied to arid and semi-arid bare soil and vegetation covered surface.

(1) It is found that when using different $S$ values in the same area, the soil water retrieval value based on LUT method decreases with the increase of $S$ value through experiments,. 
(2) Through a lot of experiments, it is found that when the LUT method is used for inversion, the value of fixed $S$ is not always the same in the same coverage area.

(3) There is a good correlation between the optimal effective $S$, $l$ value and backscatter coefficient based on pixel scale.

(4) The inversion method of soil moisture based on pixel scale effective roughness and LUT is proposed in this paper. The high precision inversion results can be obtained in the area with large vegetation coverage, and the effect of vegetation cover on soil moisture inversion accuracy is avoided to some extent.

(5) The inversion method based on the optimal effective roughness proposed in this paper can effectively avoid the error of the measured roughness value.

\section{ACKNOWLEDGEMENTS (OPTIONAL)}

Thanks for the Envisat ASAR data and synchronous field observation data from the "Watershed Allied Telemetry Experimental Research" project provided by "Heihe Plan Science Data Center, National Natural Science Foundation of China"(http://www.heihedata.org).

\section{REFERENCES}

Baghdadi, N., 2002a. An empirical calibration of the integral equation model based on SAR data, soil moisture and surface roughness measurement over bare soils. International Journal of Remote Sensing, 23(20), pp. 4325-4340.

Baghdadi, N., 2002b. Gaultier S, King C. Retrieving surface roughness and soil moisture from synthetic aperture radar (SAR) data using neural networks. Canadian Journal of Remote Sensing, 28(5), pp. 701-711.

Baghdadi, N., 2005. King C, Bonnifait A. An empirical calibration of the integral equation model based on SAR data and soil parameters measurements. In: Geoscience and Remote Sensing Symposium, IEEE International. IEEE, Vol.5, pp. 2646-2650.

Baghdadi, N., 2011. Chaaya J A, Zribi M. Semiempirical Calibration of the Integral Equation Model for SAR Data in CBand and Cross Polarization Using Radar Images and Field Measurements. IEEE Geoscience \& Remote Sensing Letters, 8(1), pp. 14-18.

Baghdadi, N., 2012. Dubois-Fernandez P, Dupuis X, et al. Sensitivity of Main Polarimetric Parameters of Multifrequency Polarimetric SAR Data to Soil Moisture and Surface Roughness Over Bare Agricultural Soils. IEEE Geoscience \& Remote Sensing Letters, 10(4), pp. 731-735.

Li,Zhen., 2011. Inversion model and method of SAR parameters.Sc ience Press, pp. 32-34.

Lievens, H., 2010a. Effective roughness modelling as a tool for soil moisture retrieval from C- and L-band SAR. Hydrology \& Earth System Sciences Discussions, 7(4), pp. 151-162.

Lievens, H., 2010b. Soil moisture retrieval from C- and L-band SAR using modeled effective roughness. In: EGU General Assembly. Vol. 12, pp. 3163-3167.
Toan,T,L.,1999. Improved Observation and Modelling of Bare Soil Surfaces for Soil Moisture Retrieval. Geophysical Research Abstracts,12(1),pp.112-117..

Verhoest, N., 2008. On the Soil Roughness Parameterization Problem in Soil Moisture Retrieval of Bare Surfaces from Synthetic Aperture Radar. Sensors, 8(7), pp. 4213-4218.

\section{APPENDIX (OPTIONAL)}

Any additional supporting data may be appended, provided the paper does not exceed the limits given above.

Revised March 2018 